\title{
Carcinoid tumour of the gall bladder: two case reports and a review of published works
}

\author{
D J Deehan, S D Heys, N Kernohan, O Eremin
}

Departments of Surgery
D J Deehan
S D Heys
O Eremin
and Pathology,
University of Aberdeen,
University Medical
Buildings, Aberdeen
N Kernohan
Correspondence to:
Dr D J Deehan, Department
of Surgery, Level l, University
Medical Buildings,
Foresterhill, Aberdeen
AB9 2ZD
Accepted for publication
19 January 1993

Abstract

This paper reports on two patients with carcinoid tumours of the gall bladder who presented to the Aberdeen hospitals during the period 1970 to 1990 and reviews all previously reported cases in published works.

(Gut 1993; 34: 1274-1276)

The carcinoid tumour or argentaffinoma originates from the Kultchitsky cell, which is believed to be derived from the neuroendocrine epiblast tissue. This migrates during embryogenesis to various endodermal or mesodermal

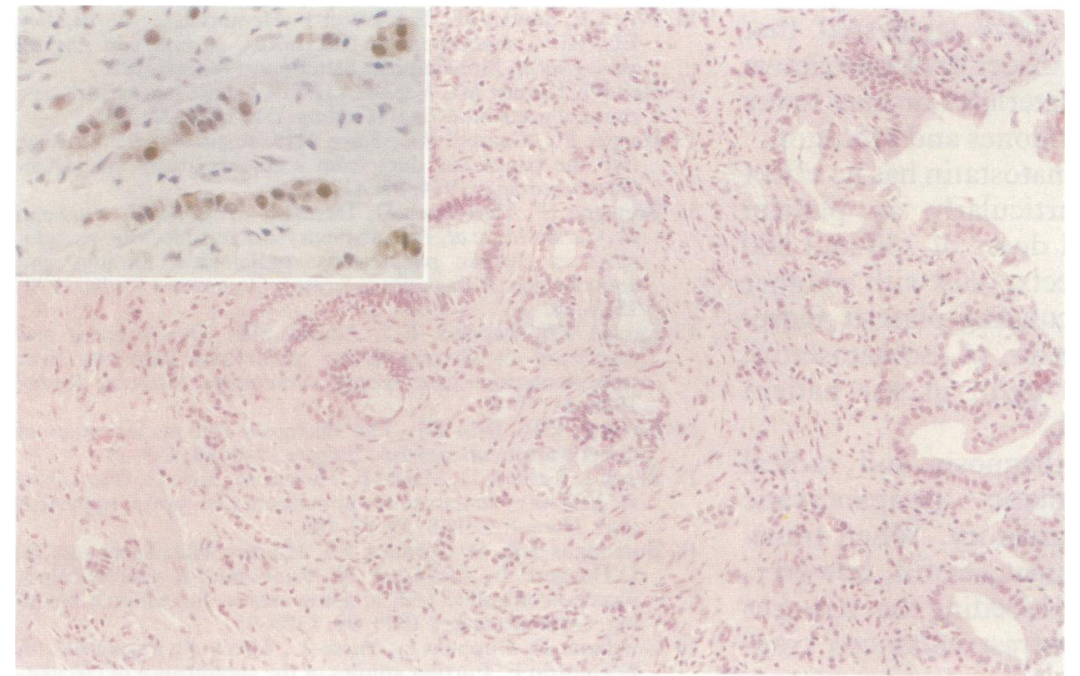

Figure 1: Carcinoid tumour discovered as an incidental finding in a cholecystectomy specimen. The tumour cells occupy the gall bladder mucosa and permeate the muscularis. Inset: the tumour cells display positive nuclear and cytoplasmic straining for $S-100$ protein.

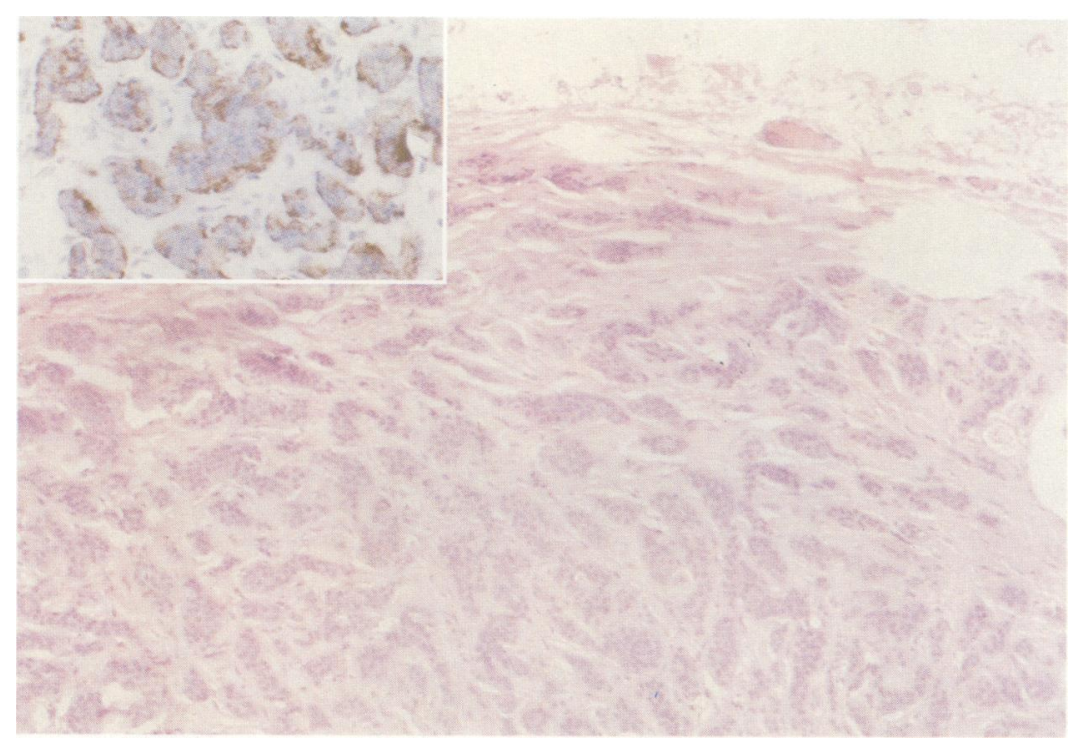

Figure 2: Carcinoid recognised macroscopically after cholecystectomy. The tumour extends to a surgical resection margin. Inset: the tumour cells are strongly positive for chromogranin. tissue.' Carcinoid tumours are capable of secreting a number of polypeptide substances and also decarboxylating amine precursors in preparation for secretion for example, histamine, serotonin, 5-hydroxytryptamine. ${ }^{23}$ They all share common cytochemical, ultrastructural, and biosynthetic properties. ${ }^{+}$

The carcinoid tumour may arise from the appendix (35\%), small bowel (25\%), colon and rectum $(19 \%)$, oesophagus and stomach $(2 \%)$, and lungs and bronchi $(14 \%) .{ }^{56}$ In the small intestine as many as $25 \%$ of cases occur as multiple localised tumours presumably because of the large number of progenitor cells in the normal tissues. ${ }^{5}$ Carcinoids arising in the biliary tract represent $0 \cdot 2-2 \%$ of all carcinoid tumours arising in the gastrointestinal tract. ${ }^{7}$ Twenty seven cases of primary carcinoid tumours of the gall bladder have been reported to date and a further 12 have been described originating from the bile ducts.?

\section{Case reports}

\section{CASE 1}

A 51 year old woman presented with a two month history of right hypochondrial, colicky pain, radiating to her back, associated with fat intolerance. Pre-operative imaging investigations showed cholelithiasis and cholecystectomy was subsequently performed. Pathological examination of the gall bladder showed chronic cholecystitis and a carcinoid tumour, $2.6 \mathrm{~mm}$ in diameter, at the gall bladder neck (Fig 1). The tumour affected the mucosa and had infiltrated into the muscularis mucosa but had been completely excised. Histologically, it was composed of trabeculae, cords, and nests of banal polygonal cells. The tumour cells had round or oval nuclei with granular chromatin and small, occasionally multiple, nucleoli. No mitotic figures were identified and the cytoplasm was eosinophilic. The tumour cells were positive for cytokeratin (CAM 5.2), neuron specific enolase, chromogranin, and S-100 protein (Fig 1+Inset). This patient is alive and well six months later.

\section{CASE 2}

A 33 year old woman presented with a six month history of right hypochrondrial pain. Radiological investigations suggested cholelithiasis and a cholecystectomy was performed. The gall bladder showed features of chronic cholecystitis but also contained a firm nodule in its wall adjacent to Hartmann's pouch. The nodule was a carcinoid tumour, $7 \mathrm{~mm}$ in diameter, composed of nests and trabeculae of banal cells with a similar morphological and immunohistochemical 
profile as shown in the previous case (Fig 2+ Inset). The tumour infiltrated into the mucosa extensively, penetrated the muscularis and extended into adjacent adipose tissue and to one of the resection margins. Tumour cells were noted encircling smal veins and arteries but there was no evidence of vascular invasion. This patient had been followed up for 15 years and is alive and well.

\section{Discussion}

The carcinoid tumour is a relatively rare type of endocrine tumour, which arises principally in the gastrointestinal tract. It comprises less than $2 \%$ of all tumour types arising in the gastrointestinal tract. ${ }^{20}$ Different histological types of carcinoid tumour have been described. The typical carcinoid tumour has a bright yellow macroscopic appearance and histologically comprises cell nests, cords, and trabeculae of uniform polygonal cell set in fibroconnective tissue stroma. The tumour cells have medium sized nuclei and have granular eosinophilic cytoplasm, with inconspicuous mitotic activity. The carcinoid cells stain for the neuroendocrine specific markers, neuron specific enolase and S-100, as in both of our cases. ${ }^{29}$ This suggests that the tumour develops by malignant transformation of mucosal neuroendocrine cells or from undifferentiated stem cells. ${ }^{31}{ }^{32}$ The characteristic ability of the midgut derived carcinoid tumours to convert ammoniacal silver to metallic silver is due to their intracytoplasmic serotonin content. ${ }^{282-34}$ The variant forms of carcinoid tumours include, the goblet cell carcinoma of the

TABLE I Clinical data on women with carcinoid tumours

\begin{tabular}{llllll}
\hline Reference & Age & Treatment & $\begin{array}{l}\text { Local } \\
\text { recurrence }\end{array}$ & Metastases & Outcome \\
\hline 8 & 66 & a & No & No & Died after two months \\
9 & 71 & b & Yes & Yes & Died after four months \\
10 & 77 & d & No & No & X \\
11 & 65 & c & No & Yes & Well at 12 months \\
12 & 64 & x & x & Yes & Found after death \\
13 & 59 & a & Yes & Yes & x \\
14 & 64 & b & Yes & Yes & x (developed carcinoid syndrome) \\
14 & 64 & c & Yes & Yes & Died after two months \\
15 & 79 & a & No & No & Well at six months \\
3 & 66 & a & No & No & Found after death \\
16 & 62 & a & No & No & Well at 18 months \\
17 & 62 & a & Yes & Yes & Died after five months of septicaemia \\
18 & 51 & c & No & Yes & Died immediately postoperatively \\
19 & 77 & a & No & No & Well at 17 months \\
19 & 76 & a & No & No & Well after > seven years \\
This study & 33 & a & No & No & Well at 15 years \\
This study & 51 & a & No & No & Well at six months \\
\hline
\end{tabular}

$\mathrm{a}=$ cholecystectomy; $\mathrm{b}=$ cholecystectomy + regional node clearance; $\mathrm{c}=$ cholecystectomy + hepatic lobectomy; $\mathrm{d}=$ cholecystectomy + omentectomy; $\mathrm{e}=$ chemotherapy; $\mathrm{f}=$ radiotherapy; $\mathrm{x}=$ not stated

TABLE II Clinical data on men with carcinoid tumours

\begin{tabular}{llllll}
\hline Reference & Age & Treatment & $\begin{array}{l}\text { Local } \\
\text { recurrence }\end{array}$ & Metastases & Outcome \\
\hline 20 & 68 & f & x & Yes & Died after eight months \\
21 & 56 & a & No & No & Well at one year \\
22 & 45 & a & No & No & Well at five years \\
23 & 26 & a + e $+\mathrm{f}$ & Yes & Yes & Died after ll months \\
24 & 77 & c & x & Yes & x \\
25 & 51 & a & No & Yes & x \\
26 & 71 & e & No & Yes & Died after six months \\
27 & 71 & e & Yes & Yes & Died after 35 months (developed) \\
5 & x & x & x & No & carcinoid syndrome) \\
2 & x & a & No & No & Well after seven years \\
\hline
\end{tabular}

$\mathrm{a}=$ cholecystectomy; $\mathrm{b}=$ cholecystectomy + regional node clearance; $\mathrm{c}=$ cholecystectomy + hepatic lobectomy; $\mathrm{d}=$ cholecystectomy + omentectomy; $\mathrm{e}=$ chemotherapy; $\mathrm{f}=$ radiotherapy; $\mathrm{x}=$ not stated; sex of patients in reference 2 and 5 not stated. gastrointestinal tract and atypical carcinoid tumour of the lung, both of which behave more aggressively than the classic form.

All the variants possess metastatic potential, however, which is not only dependent on the site of origin but also the size of the primary lesion and its depth of invasion. The bland cytological morphology does not allow a prediction of metastatic potential to be made from histological appearances.

Primary gall bladder and biliary duct system carcinoids comprise less than $1 \%$ of all carcinoid tumours arising from any tissue or organ in the body. ${ }^{2}$ The first case of primary carcinoid tumour of the gall bladder was reported by Joel in 1929, ${ }^{12}$ and since then a further 24 cases have been described. (Tables I and II). From the published data and our two patients, the age at presentation has ranged from 26-79 years (median: 64 years). There were 17 women and eight men, two further case reports did not give details of the patient's sex. Figure 3 outlines the incidence $v$ age for each sex. The mode of presentation has varied considerably, but most cases (16) were detected coincidentally in patients presenting with acute or chronic cholecystitis secondary to cholelithiasis. The tumours were usually identified at routine histological examination of the gall bladder after cholecystectomy. The size or proximity of the tumour to the hepatic ducts has been responsible for mechanical obstruction and presentation as obstructive jaundice. Only two of the reported gall bladder carcinoids presented in this manner, whereas, one half of the documented carcinoid tumours of the extra hepatic ducts presented with obstructive jaundice. ${ }^{7}$ Furthermore, the carcinoid syndrome has been found in only two patients, both of whom had disseminated disease. ${ }^{1427}$

Pre-operative diagnosis of carcinoid tumour of the gall bladder is difficult, mainly because of its small size and limitations in the resolution of the currently available radiological imaging techniques. Nevertheless, 11 of 27 patients with gall bladder carcinoid tumours (including our two cases) had a pre-operative ultrasound examination. In seven of these patients a mass consistent with a carcinoid tumour was identified. Most of the tumours were undetected before surgery, however, and in the absence of other associated phenomena, such as the carcinoid syndrome (two cases), pre-operative diagnosis was not made.

The surgical treatment undertaken in these patients has varied, ranging from simple cholecystectomy to more extensive surgical resections, including regional lymph node clearances and hepatic lobectomy. Cholecystectomy alone was performed in 14 patients and a further four patients had, in addition to cholecystectomy, a regional lymph node clearance. Four other patients had cholecystectomy combined with hepatic lobectomy, for locally advanced disease.

The role of radiotherapy and chemotherapy in the management of these patients is unclear because it is believed that, in general, carcinoid tumours are insensitive to radiotherapy. Chemotherapy has been reported to be of palliative value in carcinoid tumours arising in other sites. $^{35}$ Radiotherapy has been used in one 


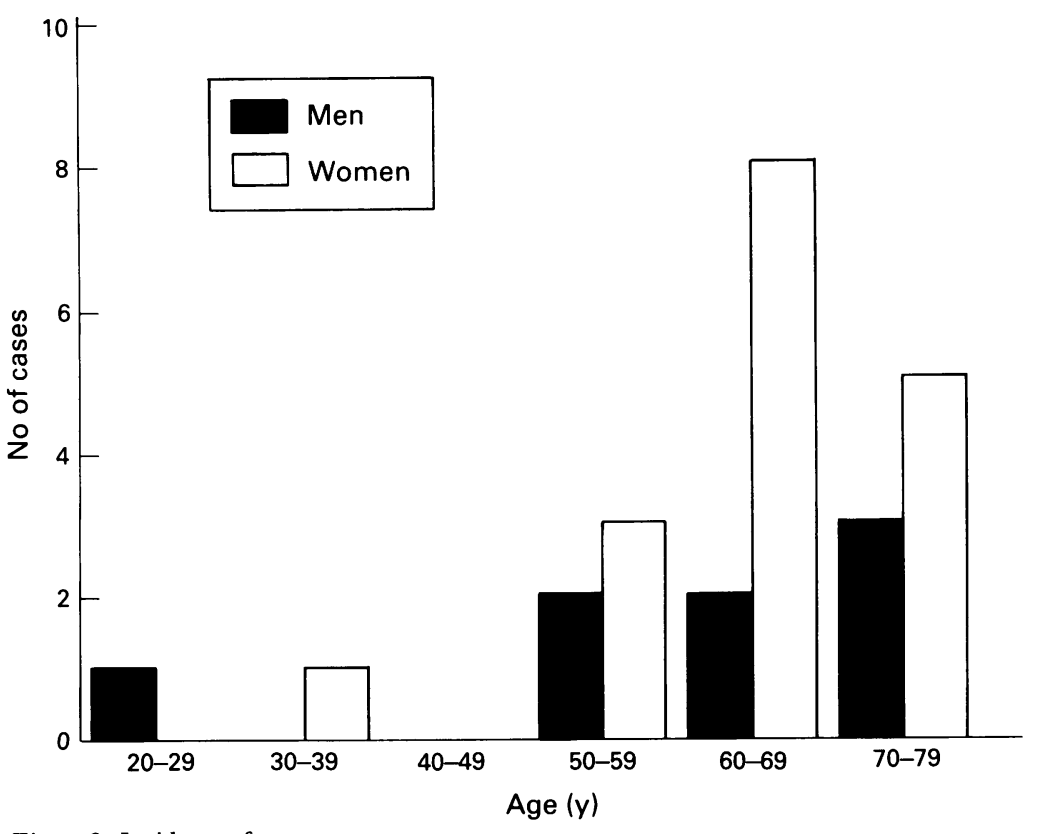

Figure 3: Incidence of carcinoid tumour of the gall bladder $\mathrm{v}$ age for both sexes. who received either chemotherapy or radiotherapy or both were dead within 35 months from the time of the original diagnosis.

1 Mullins JD, Hilliard GD. Cervical carcinoid ("argyrophil cell" carcinoma) associated with an endocervical adenocarcinoma: a light and ultrastructural study. Cancer 1981; 47: 785-90.

2 MacDonald RA. A study of 356 carcinoids of the gastrointestinal tract: Report of four new cases of the carcinoid syndrome. Am F Med 1956; 21: 867-78.

3 Porter JE, Whelan CS. Argentaffine tumours. Am $\mathcal{f}$ Cancer 1939; 36: 343-58

4 Pearse AG. The diffuse neuroendocrine system and the apud concept: related 'endocrine' peptides in brain, intestine, pituitary, placenta and anuran cutaneous glands. Med Biol 1977; 55: 115-25.

5 Godwin JD: Carcinoid tumours: an analysis of 2837 cases. Cancer 1975; 36: 560-9.

6 Kuiper DH, Gracie WA, Pollard HM. Twenty years of gastrointestinal carcinoids. Cancer 1970; 25: 1424-30

7 Rugge M, Sonego F, Militello C, Guido M, Ninfo V. Primary carcinoid tumour of the cystic and common bile ducts. Am $\mathcal{F}$ Pathol 1992; 16: 802-7.

8 Bosse MD. Carcinoid tumour of the gallbladder. Arch Pathol 1943; 35: 898-9.

9 Cavazzana AO, Fassina AS, Tollot M, Ninfo V. Small cell carcinoma of gallbladder. In immunocytochemical and ultrastructural study. Pathol Res Pract 1991; 187: 472-6.

10 Fish DE, Al-Izzi M, George PP, Whitaker B. Combined endocrine cell carcinoma and adenocarcinoma of the gallbladder. Histopathology 1990; 17: 471-2.

11 Gaffney PR, Coyle LJ. Carcinoid tumour of the gallbladder associated with a meningioma. Ir $\mathcal{F}$ Med Sci 1978; 147: 318-21.

patient with a gall bladder carcinoid as adjuvant therapy ( 4000 rads to the gall bladder bed) after cholecystectomy and hepatic resection for a locally advanced tumour. In addition, however, this patient also received combination chemotherapy (CCNU, cytosine arabinoside and 5-fluorouracil). Despite this, the carcinoid tumour continued to progress but further chemotherapy with mitomycin C, doxorubicin, and 5-fluorouracil resulted in tumour regression. This response was short lived, however, and both the local and distant disease subsequently progressed, resulting in death of the patient 21 months after initial diagnosis. ${ }^{23}$ Two further patients have received chemotherapy for extensive local disease or metastatic disease (mechlorethamine hydrochloride, benedryl, compazine, sansert), given either intravenously or by infusion into the hepatic artery. ${ }^{2627}$ Although both patients improved symptomatically, albeit for a brief period, one died after six months and the second patient died after 35 months.

Prognostic factors have not been identified in patients with gall bladder carcinoids and the usual criteria for judging malignancy, such as anaplasia and mitotic figures, are unreliable when assessing the histological appearances..$^{35}$ Malignancy is determined by evidence of tumour invasion of adjacent tissues and structures. ${ }^{36}$ If the tumour is localised to the gallbladder wall, however, with no evidence of intraperitoneal or metastatic spread, then these patients have a good prognosis, with 9 of 10 such patients being disease free at the time of reporting.

From the published work, including our two case reports, overall survival data have been documented for 18 of 27 patients. Ten patients were known to be alive at the time of reporting and patient follow up has ranged from 0 to 184 months. The median survival of all patients is 11 months, but it is interesting to note that this was longer in men than women (18 v 12 months), although further follow up data are required. The addition of chemotherapy or radiotherapy, or both did not change survival. All the patients 12 Joel W. Karzinoid der Gallenblasse. Zentral-bl Allg Pathol
1929; 46: 1-4.

13 McLean CA, Pederson JS. Endocrine cell carcinoma of the gallbladder. Histopathology 1991; 19: 173-6.

14 Noda M, Miwa A, Kitagawa M. Carcinoid tumours of the gallbladder with adenocarcinomatous differentiation: a morphologic and immunohistochemical study. $A m \mathcal{F}$ Gastroenterol 1989; 84: 953-7.

15 Papotti M, Galliano D, Monga G. Signet ring carcinoid of the gallbladder. Histopathology 1990; 17: 255-9.

16 Tanaka K, Lida Y, Tsutumi Y. Pancreatic polypeptideimmunoreactive gallbladder carcinoid tumour. Acta Pathol fpn 1992; 42: 115-8.

17 Lida Y, Tsutsumi Y. Small cell (endocrine cell) carcinoma of the gallbladder with adenocarcinomatous components. Acta Pathol fpn 1992; 42: 119-25.

18 Wisniewski $M$, Toker C. Composite tumour of the gallbladder exhibiting both carcinomatous and carcinoid patterns. Am $\mathcal{F}$ Gastroenterol 1972; 58: 633-7.

19 Yamamoto M, Nakajo S, Miyoshi N, Nakai S, Tahara E. Endocrin cell carcinoma (carcinoid) of the gallbladder. $A m \dot{F}$ Surg Pathol 1989; 13: 292-302.

20 Barnes TG. Carcinoid of the gallbladder. Surgery 1952; 32: 723-37.

21 Barone GW, Schaefer RF, Counce JS, Eidt JF. Gallbladder and gastric argyrophil carcinoid associated with a case of Zollinger-Ellison syndrome. Am $\mathcal{F}$ Gastroenterol 1992; 87: Zollinger-4.

22 Bergdahl L. Carcinoid tumours of the biliary tract. Aust NZ 7 Surg 1976; 46: 136-8.

23 Bosl JG, Yagoda A, Camara-Lopes LH. Malignant carcinoid of the gallbladder: third reported case and review of the literature. F Surg Oncol 1980; 13: 215-22.

24 Mochizuki M. Minute carcinoid tumour of the gallbladder. Acta Pathol fpn 1991; 41: 383-5.

25 Saxton CR. Unusual presentation of carcinoid tumour as acute cholecystitis. South Med f 1983; 76: 947-8.

26 Schiffman MA, Juler G. Carcinoid of the biliary tract. Arch Surg 1964; 89: 1113-5.

27 Silverman JM. Case report 659. Skeletal Radiol 1991; 20: 149-51.

28 Masson P. Carcinoids (argentaffin-cell tumours) and nerve hyperplasia of the appendicular mucosa. Am F Pathol 1928;

29 Lundqvist $M$, Wilander E. Subepithelial neuroendocrine cells and carcinoid tumours of the human small intestine and regard to serotonin, neuron-specific enolase and S-100 protein reactivity. F Pathol 1986; 148: 141-7.

30 Whitehead R, ed. Gastrointestinal and oesophageal pathology. Edinburgh: Churchill Livingstone, 1989: 629-41.

31 Wilander E, Portela-Gomes G, Grimelius L, Westermak P. Argentaffin and argyrophil reactions of human gastrointestinal carcinoids. Gastroenterology 1977; 73: 733-6.

32 McKirdie M. Carcinoids of the gastrointestinal tract. $A m \mathcal{F}$ Surg 1966; 112: 257-63.

33 Barter R, Pearse AGE. Detection of 5-hydroxy-tryptamine in mammalian enterochromaffin cells. Nature $1953 ; 171: 810$.

34 Williams ED, Sandler $M$. The classification of carcinoid tumours. Lancet 1963; i: 238-9.

35 Jute DL, Bell RH Jr, Penn I, Powers J, Kolinjkivadi J. Carcinoid tumour of the biliary system case report and literature review. Dig Dis Sci 1986; 32: 763-9.

36 Kaplan EL. The carcinoid syndromes. In; Friesen SR, ed. Surgical endocrinologv: clinical syndromes: Philadelphia: J B Lippincott, 1978: 120-47. appendix. A comparative immunohistochemical study with 